tions in Latin America.

The intended purpose of CAT is to increase the transparency and comparability of different qualifications within and between countries in Latin America and to expedite the recognition of qualifications for further academic studies and/or professional purposes. CAT has been designed as both an electronic and paper document and will be beneficial for students, higher education institutions, employers, and professional associations.

\section{Next Steps}

The widespread adoption and implementation of SICA and CAT are critical next steps for higher education institutions, organizations, and governmental bodies at local, national, and regional levels. The work to promote the use of SICA and CAT will include a wide variety of activities that will differ from country to country and even from institution to institution. At the regional level there is an opportunity to have these two instruments directly linked to the Latin American Regional UNESCO Convention on the Recognition of Qualifications. At the current time, important efforts are being made to update and promote the use of this UNESCO Regional Convention given the diversity of new providers, new programs, new types of qualification, and the increasing mobility of students and new graduates seeking further education or employment in other countries. It is timely that SICA, CAT, and the UNESCO Convention on the Recognition of Qualifications can collectively and individually contribute to the quality of higher education in Latin America, facilitate a more transparent and common system for the recognition of qualifications and the accumulation/transfer of academic credits, and help create a vibrant regional community of higher education in Latin America.

\section{The German “Initiative for Excellence" and the Issue of Ranking}

\section{Barbara M. КeHM}

Barbara M. Kehm is professor in the Centre for Research on Higher Education and Work at the University of Kassel. Address: Centre for Research on Higher Education and Work, University of Kassel, Mönchebergstr. 17, 34109 Kassel, Germany. E-mail: kehm@hochschulforschung.uni-kassel.de.

Tn January 2004, the then minister for education and 1 research of the federal German government-the social democrat, Edelgard Bulmahn-went public with the idea to organize nationwide competition among existing universities for considerable extra funding and thus to identify about Io universities that showed potential to become elite universities. This proposal caused an outcry among most of the relevant stakeholders in German higher education and broke a longstanding social democratic taboo-by supporting and promoting elite institutions. Ever since (as well as prior to) World War II, the social democratic approach to education and higher education had been one of open access, equal opportunity, and education as a public rather than a private good - and hence no tuition fees, and treatment of higher education institutions of a single type as basically all the same. These perspectives did not necessarily equal a contradiction to rankings and elite institutions, but it was argued that the money given to the few would degrade the others and take much-needed funding away from them.

As the only stakeholder group supporting-even applauding - the initiative, the employers argued that German higher education institutions were good on average but that there was a lack of "lighthouses."

The ministers responsible for education and higher education of the 16 German states remonstrated immediately against the proposal.

The ministers responsible for education and higher education of the 16 German states remonstrated immediately against the proposal. While they were interested in getting money from the federal government for higher education, they strongly disliked what they interpreted as another attempt of the federal government to meddle in an area for which they considered themselves to be responsible. They insisted on negotiations, which were started immediately.

\section{The COMPRomise}

In March 2004 the federal government and state governments agreed on a compromise consisting of a concept of competition, although funding issues were still under negotiation. Basically, universities had the opportunity to compete within three categories for extra support, by submitting respective proposals: (a) graduate schools, (b) centers of excellence with international reputation, and (c) whole institutions aiming to become elite universities. To become eligible for the competition to become an elite university, an individual institution had to succeed in getting funding for at least one graduate school and one center of excellence. In addition, the institution had to submit a coherent and convincing development concept.

In June 2004 , the funding issue was finally agreed upon. Until 20I0, the federal government and the state governments plan to invest, altogether, $€$ I.9 billion (about US\$2.3 billion) into this initiative for excellence. From 2006 until 2010, the federal government will contribute $€_{250}$ million annually to the project and the German states $€_{\mathrm{i} 30}$ million (together about 
US\$453 million annually). Extra funding was to be provided to the following three categories targeted by the initiative: (a) about 40 graduate schools, to promote the education and training of junior research staff, with each school receiving approximately $€_{\text {I }}$ million annually; (b) about 30 centers of excellence, to promote cutting-edge research, with each center of excellence receiving approximately $€ 8$ million annually; and (c) the Io top universities, on the basis of their profiles and research strengths, to promote the further structural development of higher education institutions in Germany-with each university receiving about $€_{25}$ million additional funding per year.

\section{Who Gets What?}

A joint commission was formed, composed of representatives of the German Research Association (the equivalent of a research council) and the strategic commission of the Science Council (one of the most influential buffer bodies in German higher education). The task of the commission was to formulate guidelines for the submission of proposals in the three higher education categories and to organize the process. It was decided to organize the selection process in two stages. German universities were first asked to submit general concepts in any of the three categories (graduate schools, clusters of excellence and/or institutional development concepts). Only after the first round of selection, universities that had been successful would be asked to submit fully detailed proposals.

On January 20, 2006, the commission announced the results of the first round of decisions. For universities that had submitted a concept, this was a day of hope and fear because it had been made public already that not all proposals would be accepted. A rejection was expected to backfire on the reputation of the whole university. The mass media had already been speculating for weeks about which universities might be among the Io chosen to become, officially, the first German elite universities.

For the category "graduate schools," I35 proposals were submitted, with few universities submitting more than one proposal. Of these proposals, 39 were accepted. For the category "clusters of excellence," I57 proposals were submitted. Again, some universities had submitted more than one proposal. Altogether 4I proposals were accepted. With 4 accepted proposals in this category, the University of Munich was the most successful higher education institution. Finally, 27 proposals were submitted in the category "institutional development concepts." On the basis of these proposals, the future elite universities were selected, and the results were disappointing for those universities that were rejected. The chosen Io are: Technical University Aachen, Free University Berlin, University of Bremen, University of Freiburg, University of Heidelberg, Technical University Karlsruhe, University of Munich, Technical University of Munich, University of Tübingen, and University of Würzburg.

The regional distribution of these universities is interesting as well. Four of them are located in the state of Baden-
Württemberg, three in Bavaria, and one each in NorthrhineWestfalia, Bremen, and Berlin. Looking at the subject distribution, about one-third of the successful applications in the category "clusters of excellence" came from the medical and life sciences, one-quarter each from the natural sciences and the engineering sciences, and somewhat more than Io percent from the humanities and social sciences. In the category "graduate schools" it is notable that many of the proposals had a strong interdisciplinary orientation, and the others were approximately equally distributed over the subject groups.

Altogether 36 different German universities will be asked to

Basically, universities had the opportunity to compete within three categories for extra support, by submitting respective proposals.

submit fully detailed proposals in the respective categories. The next step of the selection will be finished in October 2006 .

\section{And Future Perspectives?}

Although the initiative for excellence is not officially regarded as a move to introduce ranking into the German higher education system, it is an attempt to differentiate the institutional landscape to a certain extent. Interestingly, the direction of this type of differentiation tends to create a tension with the development triggered by the Bologna reform process-namely, the introduction of a tiered system of study programs and degrees according to three cycles: bachelor's, master's, and PhD programs and degrees. In Germany as well as in other European higher education systems that can be characterized essentially as binary systems consisting of universities and Fachhochschulen or their equivalents, the Bologna reforms have triggered a blurring of boundaries between the two institutional types. Although awarding doctoral degrees continues to remain the sole privilege of universities, both types of institutions can now offer bachelor's as well as master's programs and the distinction between professional master's programs and research master's programs is not always clear. This has led to a certain amount of competition between the two institutional types at the master's level.

The initiative for excellence, however, only targets universities. Fachhochschulen could not apply. Experts of the German higher education system basically agree that the initiative will eventually lead to a new form of differentiation. There will be a small group of top universities forming the "elite cluster." A larger group, mostly of universities in a sort of middle range, will exist that view themselves as solid research universities but will only have a slight opportunity to move into the top group. Finally, there will be another large group mainly of Fachhochschulen but also a number of universities that will be competing with one another largely for bachelor's-degree stu- 
dents. These institutions might offer some master's programs as well, but there will be little research and activities will concentrate mainly on teaching. The interesting areas in this kind of institutional diversification will be at the margins, involving movement from the top group to the middle group and vice versa as well as movement from the middle group to the lower group and vice versa. This does not necessarily entail a determination of a certain place for each individual institution on a given ranking list but rather a grouping or clustering.

What can be observed already now is the fact that this initiative did indeed trigger a lot more competition among German universities than ever before. Whether it will also turn out to be the first step in establishing a ranking of German universities remains to be seen.

\section{Shaping a New Higher Education Policy for Jamaica}

\section{TERENCE Frater}

Terence Frater is a doctoral candidate and graduate assistant in the Comparative, International, Development Education Centre at the Ontario Institute for Studies in Education, University of Toronto. E-mail: tfrater@oise.utoronto.ca.

When Jamaica included its higher education sector in the General Agreement on Trade in Services (GATS), it exposed the sector to the regulatory framework of the World Trade Organization (WTO). The country became committed to GATS out of a political culture of liberalization and a desire to expand access in the sector. Greater participation by foreign providers was expected to facilitate this expansion, although there were no clear policy strategies or appropriate regulatory mechanisms to cope with the emerging dynamics within the sector. This commitment has recently been reaffirmed, however, at a time when the higher education system is required to support national development and serve as a foundation for social mobility. Jamaica must now endeavor to craft a policy framework for the sector that captures its strategic intent while complying with its obligations as a member of the WTO.

\section{Higher Education Institutional Arrangements}

Higher education of any sort did not materialize for Jamaica until the I83os, when colleges began to be established for the first time in the small British colonies of the Caribbean. The first university, the University of the West Indies, was established in 1948 in Jamaica, to serve all these English-speaking countries. The country has done much since attaining independence in I962, and more so since the reforms of the I970s, to make higher education accessible to the average Jamaican.
The higher education landscape now consists of four universities (two private and two public), and includes six teachers colleges, five community colleges, and several technical/vocational training institutes, specialist colleges, and professional educational associations. This is the most diverse institutional framework in the English-speaking Caribbean.

\section{Foreign Higher Education Providers}

In the face of limited public resources to expand access, the participation of foreign providers is fully supported by Jamaican policymakers. These providers supply higher educational services using all the modalities specified in the GATS classifications. Within the last decade, their number has climbed from 3 to Io, and others are in discussions to enter the marketplace. Owing to their flexibility, foreign providers attract students who fail to meet the matriculation requirements of the public institutions or who are excluded as a result of infrastructure limitations. More significantly, however, they meet the needs of previously underserved working professionals who can now pursue programs at times and places that more conveniently fit their home and work schedules.

Concerns have recently been raised about the role of these foreign providers and the quality of their programs. With the creation of the University Council of Jamaica in 1987, the country has managed to maintain a high standard of outcomes through a rigorous accreditation process. Thus far, foreign institutions have sought accreditation for all their programs.

Jamaica must now endeavor to craft a policy framework for the sector that captures its strategic intent while complying with its obligations as a member of the WTO.

However, the institutional diversity that now exists and the increased complexity of supplying higher education services present challenges for the council based on its original mandate and regulatory authority. Steps are therefore being taken to strengthen the legislative framework that governs the council and to modernize its capabilities, which will ensure that it can continue to function effectively in the emerging paradigm. The government has committed to providing the necessary resources to accomplish this task.

\section{Jamaica's Higher Education Policy Imperatives}

Jamaica emerged from its ideological struggles of the I970s and I980 embracing the free-market economic model and determined to "free up" the economy with the acceleration of privatization and liberalization. The higher education sector today is a reflection of the country's colonial past and this independent-minded approach to the future. However, in the face 